\title{
Medical History Completion Status
}

National Cancer Institute

\section{Source}

National Cancer Institute. Medical History Completion Status. NCI Thesaurus. Code C83337.

A term used to describe the state or condition of the completeness of the medical history data. 